\title{
In Vitro and in Vivo Antioxidant Related Effects of Rosemary (Rosmarinus Officinalis L.) Extracts in Humans
}

\author{
Yousif Yahia Bilto $^{1,}$, Nessrin Ghazi Alabdallat ${ }^{2}$ \\ ${ }^{1}$ Department of Biological Sciences, the University of Jordan, Amman, Jordan \\ ${ }^{2}$ College of Applied Medical Sciences, Majmaah University, Majmaah, Saudia Arabia
}

\section{Email address:}

bilto@ju.edu.jo (Y. Y. Bilto)

\section{To cite this article:}

Yousif Yahia Bilto, Nessrin Ghazi Alabdallat. In Vitro and in Vivo Antioxidant Related Effects of Rosemary (Rosmarinus Officinalis L.) Extracts in Humans. American Journal of Clinical and Experimental Medicine. Vol. 3, No. 5, 2015, pp. 213-221. doi: 10.11648/j.ajcem.20150305.13

\begin{abstract}
Rosemary (Rosmarinus officinalis L.) belongs to the family Lamiaceae (Labiatae) is a well-known aromatic plant used all around the world for different medicinal purposes. Aims: The present work aimed to investigate antioxidant related effects of rosemary in humans by in vitro and in vivo studies. Study design: Chemical antioxidant assays and venous blood from healthy volunteers were used to conduct in vitro experiments. For in vivo study, nine healthy volunteers, each received orally $250 \mathrm{ml}$ of aqueous extract of rosemary daily for 5 days. Venous bloods were taken before and one hour after the first dose of aqueous extract (sample I and II respectively) and then one day after the last dose of day five (i.e. day 6, sample III). The first blood taken before the first dose (i.e. sample I), served as control for the next samples of II and III. Methodology: The following assays were performed: total antioxidant capacity (TAC), reducing power, scavenging activity of DPPH, scavenging activity of $\mathrm{OH}$, iron chelating ability, erythrocyte reduced glutathione (GSH), malonyldialdehyde (MDA), protein carbonyl (PC), superoxide dismutase (SOD), percentage hemolysis, serum total antioxidant status (TAS) and serum selected biochemical tests. Results: Rosemary extract showed efficient total antioxidant capacity, reducing power, scavenging activity of DPPH, scavenging activity of $\mathrm{OH}^{\cdot}$ and a reasonable iron chelating ability. Pre-incubation of erythrocytes in vitro with methanolic extract of rosemary then exposed to $\mathrm{H}_{2} \mathrm{O}_{2}$ decreased significantly MDA production (i.e. anti-lipid-peroxidant), $\mathrm{PC}$ production (i.e. anti-protein-oxidant) and oxidant hemolysis (i.e. anti-hemolytic) in a concentration dependent manner. Oral administration of aqueous extracts of rosemary to healthy volunteers, for 5 days, increased significantly serum TAS $(18 \%$ increase), erythrocyte GSH (72\% increase), erythrocyte superoxide dismutase (SOD) (21\% increase) and decreased significantly erythrocyte MDA (17\% decrease), with no effect on serum biochemical tests for kidney, liver, cardiac and pancreatic, compared to 0 time administration. Conclusion: Rosemary extracts have efficient in vitro and in vivo antioxidant related effects. As the present findings are obtained in healthy humans with no oxidative stress, this indicates that rosemary can improve the base line of the defense mechanisms against possible oxidative stress, with no adverse effects, thus decreasing susceptibility or preventing the progress of pathological conditions related to oxidative stress.
\end{abstract}

Keywords: Rosemary, Total Antioxidant Status, Lipid Peroxidation, Protein Carbonyl, MDA, GSH, Superoxide Dismutase, Medicinal Plants, Serum Biochemical Tests, in Vitro, in Vivo

\section{Introduction}

Rosemary (Rosmarinus officinalis L.) belongs to the family Lamiaceae (Labiatae) is a well-known aromatic plant used all around the world for different medicinal purposes. Recent research has shown that rosemary extracts have a variety of pharmacological activities, such as antioxidant, antimicrobial, cognition-improving, cancer chemoprevention, anti-diabetic, DNA-protective, choleretic, hepatoprotective, a stimulant and mild analgesic, and it has been considered as one of the most effective herbs for treating headaches, poor circulation, inflammatory diseases, and physical and mental fatigue [1-6]. Most pharmacological effects of rosemary are the consequence of high antioxidant activity of its main chemical constituents, which include carnosol, carnosic acid, ursolic acid, rosmarinic acid, and caffeic acid. The potent antioxidant properties of rosemary have been mainly attributed to its major diterpenes, carnosol and carnosic acid, 
as well as to the essential oil components $[7,8]$. Rosemary is one of the most effective spices widely used in food processing as well it is the only spice commercially available for use as an antioxidant in europe and the united states.

The antioxidant related effects of rosemary and its components have been studied in various in vitro and in vivo models. In vitro models showed that rosemary extracts and its components have free radical scavenging and anti-lipid peroxidant activities by various in vitro antioxidant assays [814]. Animal in vivo models showed under oxidative stress conditions that rosemary significantly lowered induced lipid peroxidation and raised the levels of reduced glutathione (GSH), and the antioxidant enzymes of catalase, peroxidase, glutathione peroxidase (GPx), glutathione reductase (GR), and glutathione S-transferase (GST) [15-19].

Free radicals and reactive oxygen species are continuously produced in the human body. These oxygen species are the cause of cell damage and the initiation and progression of chronic diseases. Therefore, body systems must be protected from oxidative injury through lines of defense that includes intracellular antioxidants such as reduced glutathione (GSH), superoxide dismutase (SOD), glutathione peroxidase (GPx), glutathione reductase (GR), glutathione S-transferase (GST) and catalase, and extracellular antioxidants such as vitamins, micronutrients, carotenoids, polyphenolics and other bioactive compounds [20,21].

Despite the large number of in vitro and in vivo animal studies performed on rosemary extract and its essential oil, surprisingly no clinical studies are available on humans. However, we found only two recent studies in litrature, one by Abdulrahim Al Jamal [22] who found that $3 \mathrm{~g}$ of rosemary leaves powder given dialy to healthy subjects and DM type-2 patients for 4 weeks improved significantly fasting blood glucose and lipid profile in DM patients, with no effects on these parameters in healthy subjects. The second study by Labban et al. [23] who found that 5 and $10 \mathrm{~g}$ of rosemary leaves powder given dialy to healthy subjects for 4 weeks improved significantly fasting blood glucose and serum lipid profile and blood peroxidation product (MDA), none of these two studies measured serum biochemical parameters other than glucose and lipid profile.

There is an epidemiological evidence that showed consumption of various herbs and spices is associated with positive health benefits, however, there is also some evidence that changes in the $\mathrm{pH}$ of gastrointestinal tract may significantly influence the structure and activity of the biologically-active compounds contained in consumed herbs. In fact, U. Gawlik-Dziki and M. Świeca [12] have found that simulation of gastric digestion in vitro, caused a significant increase in the content of total phenolics, a significant decrease in activities of DPPH radical scavenging and ferric reducing power, with no significant effect on iron chelating ability or the anti-lipid peroxidation activity of the rosemary extract, compared to the pre-digestion activities. In addition, they found different herbs behaving differently in terms of degree and type of change. Therefore, it seems reasonable to validate the potential antioxidant activities of edible herbs by testing them in vivo particularly in humans. As rosemary is one of the edible herbs widely used by the public across the world in every day life as food supplement and folk medicine, no studies could be found in letrature, testing the in vivo effects of rosemary on normal healthy humans. This could also be true for most herbal extracts. The present study therefore focused on the antioxidant related effects of rosemary on normal human volunteers after oral administration of aqueous extract for 5 days. To compare the in vivo effects with that of in vitro effects, we first tested the antioxidant properties of methanolic extract of rosemary by chemical assays and then the effect of methanolic extract of rosemary on human erythrocytes exposed to $\mathrm{H} 2 \mathrm{O} 2$ by in vitro experiments. The following assays were employed in these in vitro and in vivo studies: total antioxidant capacity (TAC), reducing power, scavenging activity of DPPH, scavenging activity of $\mathrm{OH} \cdot$, iron chelating ability, serum total antioxidant status (TAS), erythrocyte malonyldialdehyde (MDA), protein carbonyl (PC), reduced glutathione (GSH) and superoxide dismutase (SOD) and selected serum biochemical tests.

\section{Materials and Methods}

\subsection{Chemical Antioxidant Properties}

Chemical antioxidant properties of rosemary extract was evaluated by the following chemical assays as described elsewhere [24]: Total antioxidant capacity (TAC) measured as ascorbic acid equivalent (AAE). Reducing power measured as absorbance $\left(\mathrm{A}^{0}\right)$ at $700 \mathrm{~nm}$, with ascorbic acid being used as standard, an increase in absorbance was interpreted as increase in reducing activity of extract. Scavenging activity of DPPH, scavenging activity of $\mathrm{OH}$. and iron chelating ability were measured as $\mathrm{IC}_{50}$ value, defined as the concentration of the antioxidant needed to scavenge $50 \%$ of present $\mathrm{DPPH}$ or $\mathrm{OH} \cdot$ radicals or to chelate $50 \%$ of present $\mathrm{Fe}^{2}$ ions in the test solutions respectively.

\subsection{In Vitro Study Design}

Venous blood from healthy university student volunteers of either sex, aging 19-30 years, was obtained by vein puncture in heparin tubes. Heparinized blood samples were centrifuged, and then the plasma and buffy coat layer were removed. Packed erythrocytes were washed three times with cold phosphate buffered saline (PBS). Washed erythrocytes were exposed to $10 \mathrm{mM} \mathrm{H} \mathrm{H}_{2} \mathrm{O}_{2}$ with and without methanolic extract of rosemary and then used for determination of MDA, $\mathrm{PC}, \mathrm{GSH}$ and percentage hemolysis.

\subsubsection{Preparation of Methanolic Extract of Rosemary}

Rosemary (dried leaves), was purchased from a local herbal store in Amman, Jordan. The dried leaves were grounded in a blender with a particular size to ensure the powder in identical size, and then $100 \mathrm{~g}$ of the powder was soaked for 5-7 days with $1000 \mathrm{ml}$ of $80 \%$ methanol at $25^{\circ} \mathrm{C}$. After filtration, the filtrate was evaporated with a rotary 
evaporator to remove the methanol under reduced pressure at $50^{\circ} \mathrm{C}$. The dry crude extract of rosemary was stored in refrigerator in dark glass bottle until use. A stock solution of $1 \mathrm{mg} / \mathrm{ml}$ from the crude extract was prepared by dissolving $0.1 \mathrm{~g}$ of dry crude extract / standard and diluted in $100 \mathrm{ml}$ of $98 \%$ methanol. This stock solution was stored in refrigerator until use for the in vitro study.

\subsubsection{Exposure of Erythrocytes to $\mathrm{H}_{2} \mathrm{O}_{2}(10 \mathrm{mM})$}

Washed erythrocyte suspensions with or without preincubation with plant extract were exposed to $\mathrm{H}_{2} \mathrm{O}_{2}$ for $1 \mathrm{hr}$ at $37{ }^{\circ} \mathrm{C}$ as described elsewhere [25]. After incubation, the suspensions were used to measure erythrocytes MDA, PC, GSH and percentage hemolysis. The final concentrations of rosemary extract were $0.2,0.4,0.6$ and $0.8 \mathrm{mg} / \mathrm{ml}$.

\subsubsection{Determination of Erythrocyte $M D A$}

Erythrocyte MDA was determined as a measure of lipid peroxidation according to stocks and dormandy's method (1971) using thiobarbituric acid (TBA) as modified by srour et al. (2000) [26]. All MDA concentrations were expressed as $\mathrm{nmol} / \mathrm{gHb}$.

\subsubsection{Determination of Erythrocyte Protein Carbonyl (PC)}

Erythrocyte PC was determined as a measure of protein oxidation using cayman's protein carbonyl assay kit [27]. All protein carbonyl concentrations were expressed as $\mathrm{nmol} / \mathrm{g} \mathrm{Hb}$.

\subsubsection{Determination of Erythrocyte Reduced Glutathione (GSH)}

Erythrocyte reduced glutathione (GSH) was determined using Ellman's method [28] with slight modification as described elsewhere [29]. All GSH concentrations were expressed in $\mathrm{mg} / \mathrm{g} \mathrm{Hb}$.

\subsubsection{Determination of Erythrocyte Percentage Hemolysis}

To induce complete hemolysis, $0.1 \mathrm{ml}$ from each cell suspension was diluted and mixed with $2.9 \mathrm{ml}$ distilled water. All samples before and after dilution with water were then centrifuged at $1200 \mathrm{x}$ for $5 \mathrm{~min}$. and hemoglobin concentration of supernatants was determined spectrophotometrically at $450 \mathrm{~nm}$. Percentage hemolysis was calculated from the ratio of the absorbance of pre- to postdiluted samples.

\subsection{In Vivo Study Design}

Nine healthy volunteers ( 4 men and 5 women) with a mean age of $41.8 \pm 7.6$ years were recruited in the study after they signed an informed consent according to the ethics committee requirements. Each volunteer received orally 250 $\mathrm{ml}$ of aqueous extract of rosemary daily for 5 days. Venous blood samples were taken before and one hour after the first dose of aqueous extract (sample I and II respectively) and then one day after the last dose of day five (i.e. day 6, sample III). The first blood sample taken before the first dose (i.e. sample I), served as control for the next samples of II and III. This study was approved by the ethics committee of the university of Jordan, and have therefore been performed in accordance with the ethical standards laid down in the 1964 declaration of Helsinki.

\subsubsection{Preparation of Aqueous Extract of Rosemary}

This was prepared as usually used by the Jordanian public in dealing with this plant. Dried rosemary leaves were purchased from the local herbal store in Amman, Jordan. $50 \mathrm{~g}$ of leaves was boiled with 2.5 L water for 10-15 min, and then left covered soaking for 3-4 hrs at room temperature, then $250 \mathrm{ml}$ of soaked aqueous extract was given orally to each individual daily for 5 days.

\subsubsection{Blood Samples}

Three blood samples were collected in gell clot activator tubes from each healthy volunteer (sample I before drinking the aqueous extract, sample II after one hour of the first dose (drinking aqueous extract ) on day one and sample III at day 6 (i.e. one day following the last dose of day five). Gell tubes were centrifuged for $10 \mathrm{~min}$ at $3000 \mathrm{xg}$ at room temperature to separate and collect serum. Then $2 \mathrm{ml}$ of distilled water added to the cells under the gell in tubes and the tubes were centrifuged for $5 \mathrm{~min}$ at $3000 \mathrm{xg}$ and the supernatant (hemolysate) was collected. All samples (serum and hemolysate) were stored frozen at $-20^{\circ} \mathrm{C}$ until analysis.

\subsubsection{Determination of Serum Total Antioxidant Status (TAS)}

Serum total antioxidant status measured by TAS kit from Randox. The results were expressed as $\mathrm{mmol} / \mathrm{L}$.

\subsubsection{Determination of Erythrocyte Superoxide Dismutas (SOD) Activity}

Erythrocyte superoxide dismutas (SOD) was measured using kit from Randox [30]. The results were expressed as $\mathrm{U} / \mathrm{gHb}$.

\subsubsection{Determination of Serum Biochemical Parameters}

The kits for determination of serum biochemical parameters were purchased commercially from Roche and 902 Hitachi analyzer used to perform the following biochemical parameters: serum sodium $(\mathrm{Na})$, potassium $(\mathrm{K})$, urea nitrogen (BUN), creatinine (CREA), uric acid (UA), albumin (ALB), total protein (TP), lactate dehydrogenase (LDH), alanine transaminase (ALT), aspartate transaminase (AST), alkaline phosphatase (ALP), creatinine phosphokinase (CPK) and amylase (AMYL).

\subsection{Statistical Analysis}

All data are reported as the mean $\pm \mathrm{SD}$., statistical analysis was performed using SPSS statistics 17. The results were compared by paired $t$-test. The results with a value of $P \leq$ 0.05 were considered significant.

\section{Results}

\subsection{Chemical Antioxidant Properties}

When the antioxidant activity of rosemary was studied by several chemical assays as shown in table 1 , total antioxidant 
capacity was $184.9 \mathrm{mg}$ AAE/g extract, ferric reducing power measured as absorbance at $700 \mathrm{~nm}$ was 1.4 compared to 3.0 for vit. $\mathrm{C}$ as positive control, DPPH scavenging activity measured as $\mathrm{IC}_{50}$ was $41.0 \mu \mathrm{g} / \mathrm{ml}$ compared to 5.8 for vit. C as positive control, $\mathrm{OH} \cdot$ scavenging activity measured as $\mathrm{IC}_{50}$ was $72.6 \mu \mathrm{g} / \mathrm{ml}$ compared to $\leq 10$ for catecholamin as positive control and iron chelating ability measured as $\mathrm{IC}_{50}$ was $241.0 \mu \mathrm{g} / \mathrm{ml}$ compared to 17.3 for EDTA as positive control. According to these results it seems that $1 \mathrm{mg}$ ascorbic acid (AA) was found to be equivalent to $5.4 \mathrm{mg}$ extract for total antioxidant capacity, to $2.1 \mathrm{mg}$ extract for reducing power and to $7.1 \mathrm{mg}$ extract for DPPH scavenging, and $1 \mathrm{mg}$ catecholamine was found to be equivalent to $\geq 7.3$ $\mathrm{mg}$ extract for $\mathrm{OH} \cdot$ scavenging, and $1 \mathrm{mg}$ EDTA was found to be equivalent to $13.9 \mathrm{mg}$ extract for iron chelating.

\subsection{In Vitro Study}

As shown in figures 1, 2, 3, exposure of human erythrocytes in vitro to $10 \mathrm{mM} \mathrm{H}_{2} \mathrm{O}_{2}$ caused a significant increase in MDA (from 14.5 to $300 \mathrm{nmol} / \mathrm{g} \mathrm{Hb}$ ), protein carbonyl (from 510 to $1420 \mathrm{nmol} / \mathrm{g} \mathrm{Hb}$ ) and hemolysis (from 1.7 to $13.8 \%$ ). Pre-incubation of erythrocytes with methanolic extract of rosemary at concentrations of $0.2,0.4$, 0.6 and $0.8 \mathrm{mg} / \mathrm{ml}$ and then exposed to $\mathrm{H}_{2} \mathrm{O}_{2}$ decreased significantly MDA production (i.e. anti-lipid-peroxidant), protein carbonyl (PC) production (i.e. anti-protein-oxidant) and oxidant hemolysis (i.e. anti-hemolytic) compared to $\mathrm{H}_{2} \mathrm{O}_{2}$ alone, in a concentration dependent manner at all concentrations. Whereas, rosemary extract had no significant effect on GSH before or after exposure to $\mathrm{H}_{2} \mathrm{O}_{2}$ (fig. 4)

Table 1. Results of the chemical antioxidant assays of rosemary. AAE denotes to ascorbic acid equivalent.

\begin{tabular}{llllll}
\hline & $\begin{array}{l}\text { Total Antioxidant } \\
\text { Capacity }(\mathbf{m g ~ A A E} / \mathbf{g})\end{array}$ & $\begin{array}{l}\text { Reducing power } \\
\left(\mathbf{A}^{\mathbf{0}} \mathbf{a t} \mathbf{7 0 0} \mathbf{~ n m}\right)\end{array}$ & $\begin{array}{l}\text { Scavenging activity of } \\
\left.\mathbf{D P P H}_{(\mathbf{I C}} \mathbf{5 0}=\boldsymbol{\mu g} / \mathbf{m l}\right)\end{array}$ & $\begin{array}{l}\text { Scavenging activity of } \\
\left.\mathbf{O H}_{(\mathbf{I C}} \mathbf{~}_{\mathbf{5 0}}=\boldsymbol{\mu g} / \mathbf{m l}\right)\end{array}$ & $\begin{array}{l}\text { Iron Chelating } \\
\left(\mathbf{I C} \mathbf{~}_{\mathbf{5}}=\boldsymbol{\mu g} / \mathbf{m l}\right)\end{array}$ \\
\hline $\begin{array}{l}\text { Rosemary extract } \\
\text { positive controls }\end{array}$ & $184.9 \pm 20.0$ & $1.4 \pm 0.005$ & $41.0 \pm 0.9$ & $72.6 \pm 2.9$ & $241.0 \pm 7.5$ \\
Catecholamin $\leq 10.0$ & EDTA $=17.3 \pm 1.0$ \\
\hline
\end{tabular}

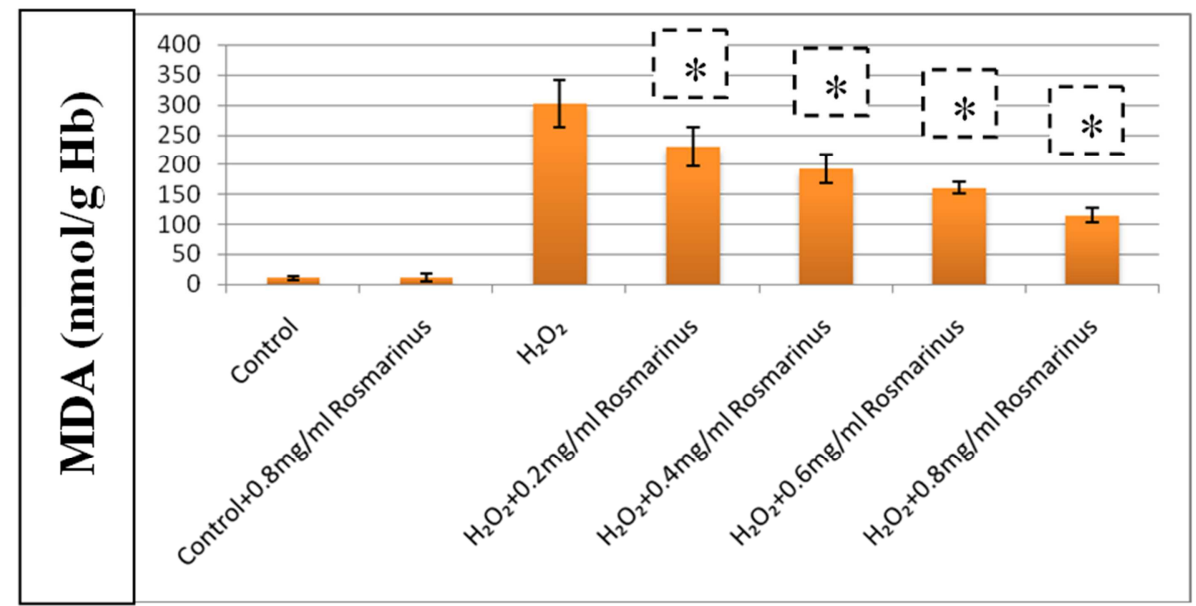

Fig. 1. Malonyldialdehyde (MDA) concentration of normal erythrocytes when incubated at $37^{\circ} \mathrm{C}$ for 60 min in the absence or in the presence of $10 \mathrm{mM} \mathrm{H}_{2} \mathrm{O}_{2}$, or in the presence of $10 \mathrm{mM} \mathrm{H}_{2} \mathrm{O}_{2}$ plus different concentrations of rosemary methanolic extract. Each column represents the mean value and bars represent the S.D. $(n=7) . * P \leq 0.05$, compared to treatment with $\mathrm{H}_{2} \mathrm{O}_{2}$ alone.

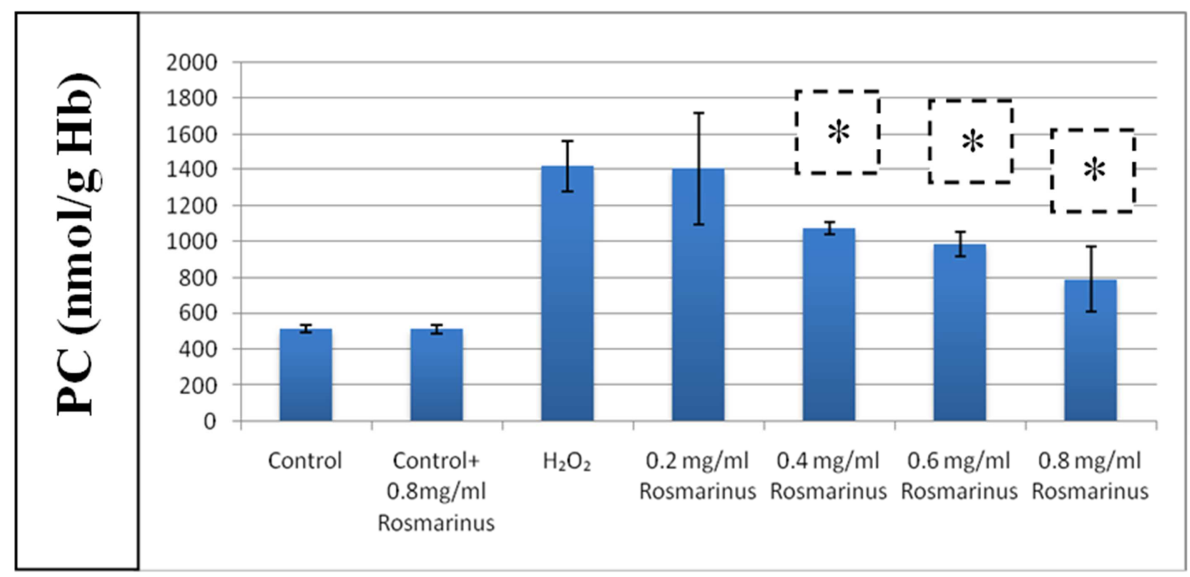

Fig. 2. Protein carbonyl (PC) concentration of normal erythrocytes when incubated at $37^{\circ} \mathrm{C}$ for 60 min in the absence or in the presence of $10 \mathrm{mM} \mathrm{H}_{2} \mathrm{O}_{2}$, or in the presence of $10 \mathrm{mM} \mathrm{H}_{2} \mathrm{O}_{2}$ plus different concentrations of rosemary methanolic extract. Each column represents the mean value and bars represent the S.D. $(n=7)$. ${ }^{*} \mathrm{P} \leq 0.05$, compared to treatment with $\mathrm{H}_{2} \mathrm{O}_{2}$ alone. 


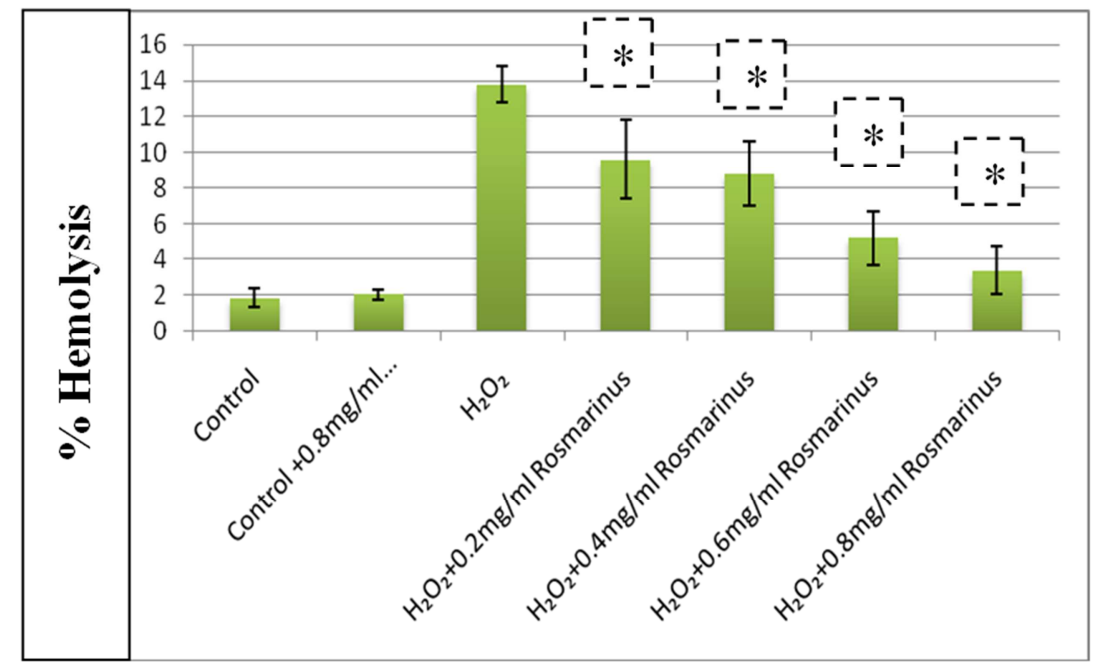

Fig. 3. Percentage hemolysis of normal erythrocytes when incubated at $37^{\circ} \mathrm{C}$ for $60 \mathrm{~min}$ in the absence or in the presence of $10 \mathrm{mM} \mathrm{H}_{2} \mathrm{O}_{2}$, or in the presence of $10 \mathrm{mM} \mathrm{H}_{2} \mathrm{O}_{2}$ plus different concentrations of rosemary methanolic extract. Each column represents the mean value and bars represent the S.D. $(n=7) . * P$ $\leq 0.05$, compared to treatment with $\mathrm{H}_{2} \mathrm{O}_{2}$ alone.

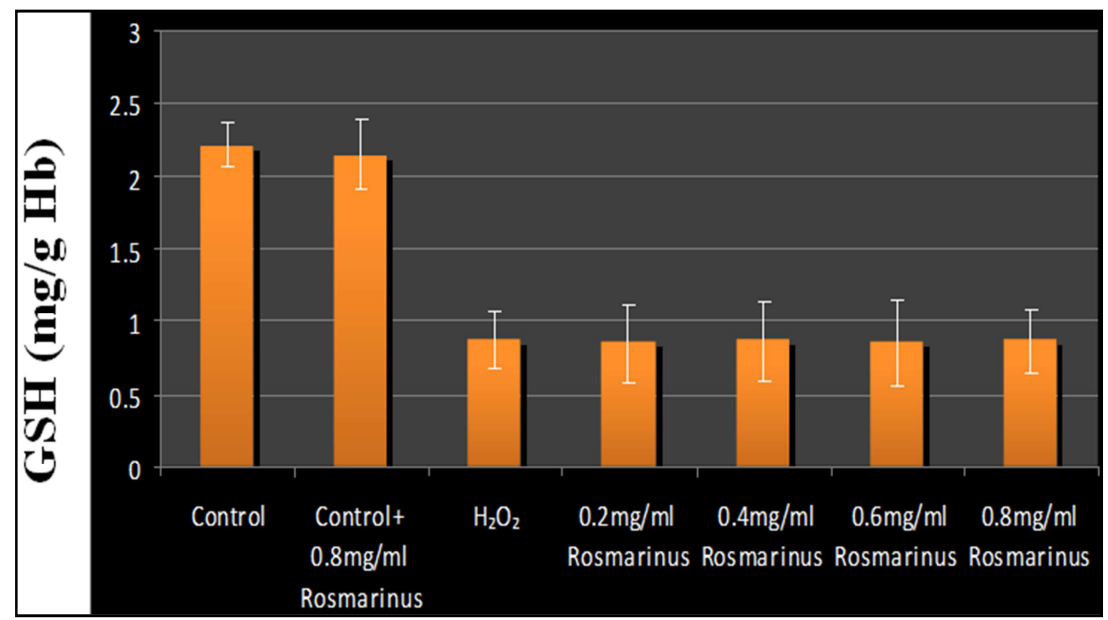

Fig. 4. Reduced glutathione (GSH) concentration of normal erythrocytes when incubated at $37^{\circ} \mathrm{C}$ for 60 min in the absence or in the presence of $10 \mathrm{mM} \mathrm{H}_{2} \mathrm{O}_{2}$, or in the presence of $10 \mathrm{mM} \mathrm{H}_{2} \mathrm{O}_{2}$ plus different concentrations of rosemary methanolic extract. Each column represents the mean value and bars represent the S.D. $(n=7)$.

Table 2. Results of the in vivo study of oral administration of rosemary aqueous extract to healthy volunteers. Each value represents the mean value \pm S.D., $(n$ $=9)$, $*$ v value $\leq 0.05$, compared to 0 time administration. NM indicates not measured.

\begin{tabular}{llll}
\hline Measured parameter & Sample I & Sample II & Sample III \\
\hline Serum TAS (mmol/L) & $1.14 \pm 0.3$ & $1.31 \pm 0.27^{*} 0.27^{*}$ & $1.35 \pm 0.20^{*}$ \\
Erythrocyte GSH $(\mathrm{mg} / \mathrm{gHb})$ & $0.82 \pm 0.13$ & $\mathrm{NM}$ & $1.41 \pm 0.23^{*}$ \\
Erythrocyte SOD $(\mathrm{U} / \mathrm{gHb})$ & $1106 \pm 118118.3$ & $\mathrm{NM}$ & $1340 \pm 134^{*}$ \\
Erythrocyte MDA(nmol/gHb) & $21.2 \pm 2.0$ & $\mathrm{NM}$ & $17.7 \pm 2.8^{*}$ \\
Serum Na (ref value=135-145 & $145.0 \pm 2.8$ & $144.5 \pm 2.1$ & $145.5 \pm 2.0$ \\
Serum K (ref value=3.7-5.2 mmol/L) & $4.4 \pm 0.39$ & $4.6 \pm 0.35$ & $4.4 \pm 0.29$ \\
Serum BUN (ref value=6-20 mg/dL) & $12.6 \pm 2.2$ & $12.6 \pm 1.5$ & $10.2 \pm 1.9$ \\
Serum CREA(ref value= $=0.6-1.3 \mathrm{mg} / \mathrm{dL})$ & $0.78 \pm 0.20$ & $0.78 \pm 0.21$ & $0.76 \pm 0.26$ \\
Serum UA (ref value $=3.5-7.2 \mathrm{mg} / \mathrm{dL})$ & $5.4 \pm 1.8$ & $5.4 \pm 1.7$ & $5.6 \pm 1.8$ \\
Serum ALB(ref value=34-54 g/L) & $47.2 \pm 4.6$ & $45.3 \pm 3.5$ & $46.6 \pm 3.4$ \\
Serum TP (ref value $=60-85 \mathrm{~g} / \mathrm{L})$ & $79.4 \pm 6.7$ & $77.4 \pm 4.8$ & $81.5 \pm 5.5$ \\
Serum ALP(ref value=55-142 & $130 \pm 86$ & $126 \pm 84$ & $126 \pm 82$ \\
Serum AST (ref value= $8-40$ & $25 \pm 6$ & $25 \pm 7$ & $24 \pm 5$ \\
Serum ALT (ref value= 7-55 & $27 \pm 15$ & $26 \pm 14$ & $27 \pm 16$ \\
Serum CPK(ref value=38-176 & $124 \pm 7171.8$ & $121 \pm 64$ & $121 \pm 50$ \\
SerumLDH(refvalue=200-450 U/L) & $403 \pm 105$ & $374 \pm 79$ & $358 \pm 66$ \\
Serum AMY(refvalue=40-140 & $51 \pm 16$ & $49 \pm 14$ & $50 \pm 15$ \\
\hline
\end{tabular}




\subsection{In Vivo Study}

The results of the in vivo study are shown in table 2. As shown in table 2, oral administration of aqueous extracts of rosemary to healthy volunteers for 5 days increased significantly serum total antioxidant status (TAS) (from 1.14 to $1.35=18 \%$ increase), erythrocyte reduced glutathione (GSH) (from 0.82 to $1.41=72 \%$ increase), erythrocyte superoxide dismutase (SOD) (from 1106 to $1340=21 \%$ increase) and decreased significantly erythrocyte malonyldialdehyde (MDA) (from 21.2 to $17.7=17 \%$ decrease) at day 6 (i.e. one day following the last dose of day five) of administration, compared to 0 time administration.

Rosemary had no significant effect on any of the following serum parameters that stayed within the reference ranges (sodium, potassium, urea nitrogen (BUN), creatinine, uric acid (UA), albumin, total protein, alkaline phosphatase (ALP), lactate dehydrogenase (LDH), alanine transaminase (ALT), aspartate transaminase (AST), creatinine phosphokinase (CPK), amylase (AMYL)) that have been measured at 0 time, 1 hour after the first dose of day 1 , or at day 6 (i.e. one day following the last dose of day five) (Table 2).

\section{Discussion}

Reactive oxygen species (ROS) may accumulate in the cell, either from excessive production or insufficient neutralization, causing oxidative damage to DNA, lipids, and proteins. Mitochondria organelles in cells are both a major source and target for ROS. This accumulation of ROS (called oxidative stress) has been shown to be a factor in the initiation and progression of many diseases. Natural antioxidants strengthen the endogenous antioxidant defenses against reactive oxygen species (ROS) and restore the optimal antioxidant/oxidant balance by neutralizing the reactive species.

Antioxidants can delay or prevent the oxidation of lipids, protiens or other molecules by inhibiting the initiation or propagation of an oxidizing chain reactions [31].

Medicinal plants contain natural substances that are known to have antioxidant activities. In recent decades, an increasing evidence indicates the positive role of traditional medicinal plants in the prevention or control of many diseases [32].

Among the herbal extracts reported to have antioxidant activity, rosemary (Rosmarinus officinalis L.) which is one of the most widely used and commercially available herb.

Various in vivo mechanisms may contribute to oxidative processes in complex systems, therefore, it is important to characterize herbal extracts by a variety of antioxidant assays. Several chemical antioxidant assays were applied in the present study to characterize methanolic extract of rosemary.

As shown in Table 1, rosemary extract have efficient total antioxidant capacity, reducing power, scavenging activity of $\mathrm{DPPH}$, scavenging activity of $\mathrm{OH}^{\cdot}$ and a reasonable iron chelating ability. These results are in agreement with previous data reported on the antioxidant activity of rosemary extract and essential oil that also showed efficient scavenging activity and a reasonable iron chelating ability $[12,13,16$, 24].

The present in vitro study on normal human erythrocytes showed that pre-incubation of erythrocytes with methanolic extract of rosemary and then exposed to $\mathrm{H}_{2} \mathrm{O}_{2}$ decreased significantly MDA production (i.e. anti-lipid-peroxidant), PC production (i.e. anti-protein-oxidant) and oxidant hemolysis (i.e. anti-hemolytic) that were caused by $\mathrm{H}_{2} \mathrm{O}_{2}$, in a concentration dependent manner (Figures 1, 2, 3). To our knowledge, the anti-protein-oxidant and anti-hemolytic activities of rosemary (Figures 2, 3) have not been reported before, whereas the anti-lipid-peroxidant activity (Fig. 1) has been reported before [12, 16, 23].

The present in vivo study on humans (Table 2) showed that oral administration for 5 days of aqueous extracts of rosemary increased significantly serum total antioxidant status (TAS), erythrocyte reduced glutathione (GSH), erythrocyte superoxide dismutase (SOD), and decreased significantly erythrocyte malonyldialdehyde (MDA). To our knowledge, these serum antioxidant enzymes in human have not been reported before to compare with, whereas the anti-lipid-peroxidant activity in healthy human has been reported before [23]. These in vivo results, however, coincide with the findings of other researchers in animals exposed to oxidative stress with various means that showed rosemary extract and essential oil improved enzymatic and non enzymatic antioxidant parameters under induced oxidative stress conditions [15-19]. As the present findings are obtained in healthy humans with no oxidative stress induction, this indicates that rosemary can improve the base line of the defense mechanisms against possible oxidative stress, thus decreasing susceptibility to diseases related to oxidative stress.

The present in vitro study showed that rosemary extract had no effect on GSH of incubated erythrocytes before or after exposure to $\mathrm{H}_{2} \mathrm{O}_{2}$ (Fig. 4). This is in contrary to the in vivo study of humans (Table 2), indicate that the in vitro antioxidant activity of the tested extract is not mediated through increasing erythrocyte GSH, probably, because the in vitro experimental condition, which lacks the nutrients, is supposed to be not suitable for the reproduction of GSH.

Absence of rosemary effect on serum LDH of healthy volunteers may indicate in vivo anti-hemolytic activity for this plant and/or absence of adverse in vivo hemolytic activity.

Absence of the effect of oral administration of aqueous extract of rosemary on serum biochemical tests that stayed within the reference ranges for kidney function (BUN,CREA), liver function enzymes and tests (ALT, AST, ALP, albumin, total protein), cardiac enzymes (CPK, LDH, AST) and pancreatic amylase, indicates absence of adverse effects on these organs. This result agrees with the findings of Moeko Noguchi-Shinohara et al [33], the only published study in litrature, who evaluated the safety, tolerability and pharmacokinetics of single dose of Melissa officinalis extract 
which contained $500 \mathrm{mg}$ rosmarinic acid. They showed that rosmarinic acid supplementation did not affect liver, kidney, or blood cell function parameters, and no adverse event was reported by any of the participants due to the study treatment, indicating a single dose of Melissa officinalis extract containing $500 \mathrm{mg}$ rosmarinic acid per day appears to be safe and tolerable in humans, but further studies may needed to investigate the safety of long-term rosmarinic acid use. This result also confirms a similar finding for some of these biochemical tests by others who gave rosemary extract or essential oil of rosemary to animals [16, 17, 34-38], and also coincides with others [16] who showed that essential oil of rosemary given to rats for seven days and then given a dose of $\mathrm{CCl} 4$ to induce liver injury significantly reduced the high serum levels of liver and kidney function tests of AST, ALT, total bilirubin, urea and creatinine that have been increased by the CCl4. Also with others [34, 39] who found that rosemary aqueous extract alleviates the nephrotoxicity induced by CCL 4 in albino rats or by gentamicin in guinea pigs.

Measurement of various biochemical laboratory tests in serum after oral intake of rosemary was also important, to see whether a given plant extract affects laboratory analysis, as many patients may go to the clinical laboratory for analysis after drinking herbal extracts that have become a common habit in public, as there are no published studies showing their might be effects on laboratory tests.

As the present study could not tell the mechanism by which rosemary increased cellular GSH in vivo and failed it in vitro and increased activity of SOD, one can speculate that either the increase in GSH triggers the increase in the enzymes dependent on it, or rosemary causes the induction of these enzymes independent of GSH. Therefore, further studies are required to gain more insight into the possible mechanisms of action.

\section{Conclusion}

Given orally to healthy humans for five days, rosemary extracts caused a significant increase in serum total antioxidant status, erythrocyte reduced glutathione, erythrocyte superoxide dismutase and decreased erythrocyte malonyldialdehyde (MDA), these results were proportional to the in vitro effects of rosemary on human erythrocytes that showed pre-incubation of erythrocytes with methanolic extract of rosemary at various concentrations and then exposed to $\mathrm{H}_{2} \mathrm{O}_{2}$ decreased significantly MDA production (i.e. anti- lipid-peroxidant), protein carbonyl (PC) production (i.e. anti-protein-oxidant) and oxidant hemolysis (i.e. antihemolytic), in a concentration dependent manner.

These in vivo and in vitro results can only be explained by the tested chemical antioxidant properties of rosemary that showed rosemary extract have efficient total antioxidant capacity, reducing power, scavenging activity of DPPH, scavenging activity of $\mathrm{OH}$ and a reasonable iron chelating ability.

The positive antioxidant related effects of rosemary on healthy humans with no adverse effects on major body systems may indicate that this plant by improving the base line of the body defense mechanisms might be helpful in preventing the occurrence or progress of pathological conditions related to oxidative stress.

\section{Acknowledgment}

We are grateful to the deanship of scientific research, the University of Jordan for the financial support to conduct this study.

\section{References}

[1] Al-Sereiti MR, Abu-Amer KM and Sen P: Pharmacology of rosemary (Rosmarinus officinalis Linn.) and its therapeutic potentials. Indian J Exp Biol 1999; 37: 124-130.

[2] Assessment report on Rosmarinus officinalis L., aetheroleum and Rosmarinus officinalis L., folium EMA/HMPC/13631/2009. 15 July 2010.

[3] Faixová, Z. and Faix, ̌̌s: Biological effects of rosemary (Rosmarinus offficinalis L.) essential oil (A Review). FOLIA VETERINARIA 2008; 52(3-4): 135-39.

[4] Rocha, J., Eduardo-Figueira, M., Barateiro, A., Fernandes, A., Brites, D., Bronze, R., Duarte, C. M., Serra, A. T., Pinto, R., Freitas, M., Fernandes, E., Silva-Lima, B., Mota-Filipe, H. and Sepodes, B: Anti-inflammatory Effect of Rosmarinic Acid and an Extract of Rosmarinus officinalis in Rat Models of Local and Systemic Inflammation. Basic \& Clinical Pharmacology \& Toxicology 2015; 116:398-413.

[5] Borhan Shokrollahi, Fardin Amini, Shahin Fakour, Mohammad Amiri Andi: Effect of rosemary (Rosmarinus officinalis) extract on weight, hematology and cell-mediated immune response of newborn goat kids. Journal of Agriculture and Rural Development in the Tropics and Subtropics 2015; 116(1): 91-97.

[6] Eilyad Issabeagloo, Parviz Kermanizadeh, Mohammad Taghizadieh and Reza Forughi: Antimicrobial effects of rosemary (Rosmarinus officinalis L.) essential oils against Staphylococcus spp. African Journal of Microbiology Research 2012; 6(23): 5039-42.

[7] Ngo SN, Williams DB and Head RJ: Rosemary and cancer prevention: preclinical perspectives. Crit Rev Food Sci Nutr 2011; 51: 946-54.

[8] O. Santana-Méridas, M. Polissiou, M. E. Izquierdo-Melero, K. Astraka, Petros A. Tarantilis, D. Herraiz-Peñalver and R. Sánchez-Vioque: Polyphenol composition, antioxidant and bioplaguicide activities of the solid residue from hydrodistillation of Rosmarinus officinalis L. Industrial Crops and Products 2014; 59: 125-34.

[9] Pérez-Fons L, Garzón MT and Micol V: Relationship between the antioxidant capacity and effect of rosemary (Rosmarinus officinalis L.) polyphenols on membrane phospholipid order. J Agric Food Chem 2010; 58(1): 161-71.

[10] Maria J. Jordán, Vanesa Lax, Maria C. Rota, Susana Lorán, and José A. Sotomayor: Relevance of Carnosic Acid, Carnosol, and Rosmarinic Acid Concentrations in the in Vitro Antioxidant and Antimicrobial Activities of Rosmarinus officinalis (L.) Methanolic Extracts. J. Agric. Food Chem 2012; 60 (38): 9603-8. 
[11] Mayara Fumiere Lemos, Mariana Fumiere Lemos, Henrique Poltronieri Pacheco, Denise Coutinho Endringer and Rodrigo Scherer: Seasonality modifies rosemary's composition and biological activity. Industrial Crops and Products 2015; 70: 41-47.

[12] Urszula Gawlik-Dziki and Michał Świeca: Effect of various $\mathrm{pH}$ conditions simulated in vivo on the activity of lipophilic antioxidants isolated from selected spices. Pol. J. Food Nutr. Sci. 2007; 57(3A): 19-22.

[13] Dorman H. J. D., Peltoketo A., Hiltunen R and Tikkanen M. J: Characterization of the antioxidant properties of de-odourised aqueous extracts from selected Lamiaceae herbs. Food Chem 2003; 83: 255-62.

[14] Viuda-Martos M, Ruiz Navajas Y, Sánchez Zapata E, Fernández-López J, and Pérez-Álvarez JA: Antioxidant activity of essential oils of five spice plants widely used in a Mediterranean diet. Flavour Frag J. 2010; 25: 13-19.

[15] Sahar, T. Ahmad; Abeer, S. Hafez; Manal, A. Hassan and Mogda, K. Mansour: Influence of Rosemary Extract on Immune Responses and Oxidative Stress in Mice Intoxicated by Aflatoxins. Nature and Science 2011; 9(10): 54-63.

[16] Aleksandar Rašković, Isidora Milanović, Nebojša Pavlović, Tatjana Ćebović, Saša Vukmirović and Momir Miko: Antioxidant activity of rosemary (Rosmarinus officinalis L.) essential oil and its hepatoprotective potential. BMC Complementary and Alternative Medicine 2014; 14:225.

[17] Manal A Emam: Comparative evaluation of antidiabetic activity of Rosmarinus officinalis $\mathrm{L}$. and Chamomile recutita in streptozotocin induced diabetic rats. Agric. Biol. J. N. Am. 2012; 3(6): 247-52.

[18] Olfat A. Khalil, Kholoud S. Ramadan, Enas N. Danial, Hanan S. Alnahdi and Najla O. Ayaz: Antidiabetic activity of Rosmarinus officinalis and its relationship with the antioxidant property. African Journal of Pharmacy and Pharmacology 2012; 6(14):1031-36.

[19] Bakirel T, Bakirel U, Keles OU, Ulgen SG and Yardibi H: In vivo assessment of antidiabetic and antioxidant activities of rosemary (Rosmarinus officinalis) in Alloxan-Diabetic Rabbits. Journal of Ethnopharmacology 2008; 116: 64-73.

[20] Packer, L, Colman, C. The Antioxidant Miracle. Canada. John Wiley \& Sons Inc. Pub. 1999.

[21] Valko, M, Leibfritz, D, Moncol, J, Cronin, MT, Mazur, M and Telser, J: Free radicals and antioxidants in normal physiological functions and human disease. Int. J. Biochem. Cell Biol. 2007; 39:44-84.

[22] Abdulrahim Al Jamal: Effect of rosemary (Rosmarinus offficinalis) on lipid profiles and blood glucose in human diabetic patients (type-2). Afr. J. Biochem. Res. 2014; 8(8): 147-50.

[23] Louay Labban, Usama El-Sayed Mustafa and Yasser Mahmoud Ibrahim: The Effects of Rosemary (Rosmarinus officinalis) Leaves Powder on Glucose Level, Lipid Profile and Lipid Perodoxation. International Journal of Clinical Medicine 2014; 5: 297-304.

[24] Yousif Yahia Bilto, Nessrin Ghazi Alabdallat and Maher Salim: Antioxidant Properties of Twelve Selected Medicinal Plants Commonly Used in Jordan. British Journal of Pharmaceutical Research 2015; 6(2): 121-30.
[25] Bilto YY, Player M, Stuart J: Rheological action of oxpentifylline and structurally related xanthine derivatives on human erythrocytes. Clinical Hemorheology 1988; 8(2): 21321.

[26] Srour, MA, Bilto, YY and Juma, M: Evaluation of different methods used to measure malonyldialdehyde in human erythrocytes. Clin. Hemorheol. Microcirc. 2000; 23:23-30.

[27] Reznick, A and Packer, L: Oxidative damage to proteins: Spectrophotometric method for carbonyl assay. Methods in Enzymology 1994; 233:357-63.

[28] Ellman, GL: Tissue Sulfhydryl (-SH) Groups. Archive of Biochemistry and Biophysiology 1951; 82:70-77.

[29] Yousif Yahia Bilto and Nessrin Ghazi Alabdallat: Ex vivo and In vivo Antioxidant Related Effects of Zingiber officinale Roscoe (Ginger) Extracts in Humans. European Journal of Medicinal Plants 2015; 7(2): 99-108.

[30] Arthur, JR and Boyne, R: Superoxide dismutase and glutathione peroxidase activities in neutrophilis from selenium deficient and copper deficient cattle. Life Sci. 1985; 36:156975 .

[31] Zheng, W. and Wang, S.Y: Antioxidant Activity and Phenolic Compounds in Selected Herbs. Journal of Agricultural and Food Chemistry 2001; 49:5165-70.

[32] Zhang, X: Traditional Medicine and WHO World Health. The Magazine of World Health Organization 1996; 2:4-5.

[33] Moeko Noguchi-Shinohara, Kenjiro Ono, Tsuyoshi Hamaguchi, Kazuo Iwasa, Toshitada Nagai, Shoko Kobayashi, Hiroyuki Nakamura and Masahito Yamada: Pharmacokinetics, Safety and Tolerability of Melissa officinalis Extract which Contained Rosmarinic Acid in Healthy Individuals: A Randomized Controlled Trial. PLoS One 2015; 10(5): e0126422.

[34] Azab El Saied Azab, Fathy Ahmed Fetouh and Mohamed Omer Albasha: Nephro-Protective Effects of Curcumin, Rosemary and Propolis against Gentamicin Induced Toxicity in Guinea Pigs: Morphological and Biochemical Study. American Journal of Clinical and Experimental Medicine 2014; 2(2): 28-35.

[35] Atef M. Al-Attar and Nessreen A. Shawush: Physiological investigations on the effect of olive and rosemary leaves extracts in male rats exposed to thioacetamide. Saudi Journal of Biological Sciences 2014; 21:473-80.

[36] Mohsen Sahraei, Rasoul Pirmohammadi and Sina Payvastegan The effect of rosemary (Rosmarinus officinalis L.) essential oil on digestibility, ruminal fermentation and blood metabolites of Ghezel sheep fed barley-based diets. Spanish Journal of Agricultural Research 2014; 12(2): 448-54.

[37] Umit Polat, Derya Yesilbag and Mustafa Eren: Serum Biochemical Profile of Broiler Chickens Fed Diets Containing Rosemary and Rosemary Volatile Oil. J. BIOL. ENVIRON. SCI. 2011; 5(13):23-30.

[38] Amera S. Abd El-Latif, Nahed S. Saleh, Tamer S. Allam and Emad W. Ghazy: The Effects of Rosemary (Rosemarinus afficinalis) and Garlic (Allium sativum) Essential Oils on Performance, Hematological, Biochemical and Immunological parameters of Broiler Chickens. British Journal of Poultry Sciences 2013; 2(2):16-24. 
[39] Saber SA and Lamfon HA: Protective effect of rosemary (Rosmarinus Officinalis) leaves extracts on carbon tetrachloride-induced nephrotoxicity in albino rats. Life science journal 2012; 9(1): 779-85. 